Research Article

\title{
Cost-minimization analysis of proton pump inhibitors in India
}

\author{
Mukunda Bharat Bargade*, Mohini Sachin Mahatme, Sachin Hiware, \\ Pallavi D. Admane
}

Department of Pharmacology, Indira Gandhi Government Medical College, Nagpur, India

Received: 04 April 2016

Accepted: 07 May 2016

*Correspondence to:

Dr. Mukunda Bharat Bargade,

Email: mukundagmc

@gmail.com

Copyright: () the author(s), publisher and licensee Medip Academy. This is an openaccess article distributed under the terms of the Creative Commons Attribution NonCommercial License, which permits unrestricted noncommercial use, distribution, and reproduction in any medium, provided the original work is properly cited.

\begin{abstract}
Background: Peptic ulcer disease significantly lowers quality of life. The proton pump inhibitors (PPIs) are the most potent suppressors of gastric acid secretion. Although similar in terms of efficacy and safety, PPIs have important differences in their costs. Prescription of costly brands adversely affects expenditure on health care system by patients. Therefore, we conducted this cost-minimization study of all available PPIs to help doctors in selecting the cheapest available option.

Methods: Cost-minimization analysis (CMA) compares the cost of equally effective therapeutic options for the given condition. The cost of all PPIs brands available was collected from CIMS (July 2015) and Drug Today (July 2015). Cost range, cost ratio and mean cost of the generic drug was calculated.

Results: 1122 PPI brands are available in India. Pantoprazole is most commonly available with 494 brands and dexrabeprazole has only 6 brands. All the PPIs are available in oral and injectable formulations except ilaprazole and dexrabeprazole which are available in oral formulations only. Omeprazole 20 $\mathrm{mg}$ and $40 \mathrm{mg}$ is the cheapest in both oral and injectable form respectively while ilaprazole $10 \mathrm{mg}$ is the costliest amongst all oral formulations and rabeprazole $40 \mathrm{mg}$ is the costliest in injectable preparations. Highest cost ratio for oral PPIs is for omeprazole $20 \mathrm{mg}$ and lowest is for omeprazole $10 \mathrm{mg}$. This variation is mostly due to large numbers of brands available for omeprazole.

Conclusions: Prescription of costly brands adversely affects patient's economy and thereby health seeking behaviour. Therefore knowledge of the doctor about drug cost and its application in practice would be an added benefit to the patient and society.
\end{abstract}

Keywords: PPIs, CMA, Acid peptic diseases, Cross-sectional study

\section{INTRODUCTION}

Inevitable changes in lifestyle and food habits of Indian population due to rapid urbanization along with excessive use of various medications are the reasons for excessive gastric acid secretion. ${ }^{1,2}$ The increased gastric acid secretion destructs mucosal lining of gastrointestinal tract leading to ulceration, erosive esophagitis, erosive gastritis and gastro esophageal reflux disease (GERD) etc. ${ }^{3}$

The prevalence of GERD in western countries ranges from $10 \%-44 \%$. Prevalence of GERD in northern Indian population is $16.2 \%$ similar to developed countries. ${ }^{4}$ In Asian countries its prevalence is increasing. ${ }^{5,6}$ Also $30 \%$ surgical ward patients suffer from acid peptic disorder. ${ }^{3}$ According to a systematic review, patients with peptic ulcer disease had significantly lower quality of life. The direct medical costs of these GERD patients based on several countries national estimate were US\$ $163-886$ per patient. ${ }^{7}$ Though various options available to treat acid peptic diseases, proton pump inhibitors (PPIs) are the most potent suppressors of gastric acid secretion. ${ }^{8}$

There are seven PPIs available for clinical use in Indian market i.e. omeprazole, esmoprazole, lansoprazole, rabeprazole, dexrabeprazole, ilaprazole and pantoprazole. ${ }^{9,10}$ These are the mainstay of treatment in gastric and duodenal ulcers, GERD, erosive esophagitis, 
self-treatment of heartburn, pathological hypersecretory conditions like Zollinger-Ellison syndrome, prevention and treatment of non-steroidal anti-inflammatory drugs (NSAIDS) associated gastric ulcers. Also, the risk of duodenal ulcers recurrence associated with $H$. pylori infection is reduced. All PPIs have found to have equivalent efficacy at comparable doses. ${ }^{8}$ Although similar to each other in terms of efficacy and safety, PPIs have important differences in their costs. Prescription of costly brands by the doctors adversely affects expenditure on health care system by patients, thereby imparts burden on patient's economy also. Therefore, we conducted this cost-minimization study by cross sectional analysis of all available PPIs brands to help doctors in selecting the cheapest available option amongst these medicines.

\section{METHODS}

The simplest type of pharmaco-economic analysis is costminimization analysis (CMA) which compares the cost of equally effective therapeutic options for the given condition. $^{11}$ All PPIs are equivalent in efficacy at comparable doses. Equivalent doses for various PPIs have been mentioned in comparison to the standard dose of omeprazole $20 \mathrm{mg}$. For $20 \mathrm{mg}$ of omeprazole, equivalent doses for esomeprazole is $20 \mathrm{mg}$, for lansoprazole is $30 \mathrm{mg}$, for pantoprazole is $40 \mathrm{mg}$ and for rabeprazole is $20 \mathrm{mg}$. ${ }^{12}$

The cost of all PPIs brands available was collected from CIMS India (July 2015) and Drug Today India (July 2015). ${ }^{9,10}$ Cost range, cost ratio and mean cost of the generic drug was calculated. Cost range is range of drug from minimum to maximum cost. Cost ratio is calculated as the quotient of maximum cost over minimum cost.

The mean cost of generic drug has been calculated as sum of the costs of all brands divided by total number of brands available for the same generic drug. While calculating mean cost, brands with price information available are considered only for adding the prices and dividing by number of brands, as considering other brands would significantly show falls decrease in mean cost value of the drug. The cost taken into consideration is per ten tablets/ capsule or per single vial. Cost is calculated in Indian National Rupees (INR).

\section{RESULTS}

Among the 1122 brands of various PPIs available in India, Pantoprazole has highest numbers of brands i.e. 494 (44\%) brands, rabeprazole has 297 (26.47\%) brands, omeprazole has total $231(20.59 \%)$ brands, lansoprazole has $52(4.63 \%)$ brands, esmoprazole has $26(2.32 \%)$ brands in the market, ilaprazole has 16 (1.43\%) brands and dexrabeprazole has only $6(0.53 \%)$ brands (Figure 1$)$.

Esmoprazole is available as $20 \mathrm{mg}, 40 \mathrm{mg}$ oral formulation and $40 \mathrm{mg}$ injectable formulation with 15, 19 and 6 brands of each respectively. Rabeprazole is available as $10 \mathrm{mg}, 20 \mathrm{mg}$ oral formulation and $20 \mathrm{mg}, 40$ $\mathrm{mg}$ injectable formulation with 20, 285, 30 and 1 brands of each respectively. Lansoprazole is available as $15 \mathrm{mg}$, $30 \mathrm{mg}$ oral formulation with 14 and 49 brands of each respectively. Pantoprazole is available as $20 \mathrm{mg}, 40 \mathrm{mg}$ oral formulation and $20 \mathrm{mg}, 40 \mathrm{mg}$ injectable formulation with 29, 418 and 2, 209 brands of each respectively.

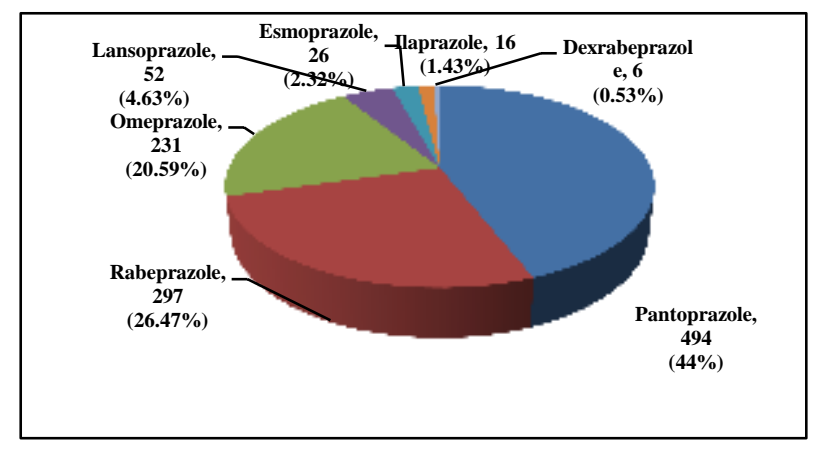

\section{Figure 1: Total brands available in the market for} each proton pump inhibitor.

Ilaprazole is available as $5 \mathrm{mg}$ and $10 \mathrm{mg}$ oral formulation with 6 and 15 brands of each respectively. Omeprazole is available as $10 \mathrm{mg}, 20 \mathrm{mg}, 40 \mathrm{mg}$ oral formulation and 40 mg injectable formulation with 13, 229, 6 and 4 brands of each respectively. Dexrabeprazole is available as $5 \mathrm{mg}$ and $10 \mathrm{mg}$ oral formulation with 3 and 6 brands of each respectively (Figure 2).

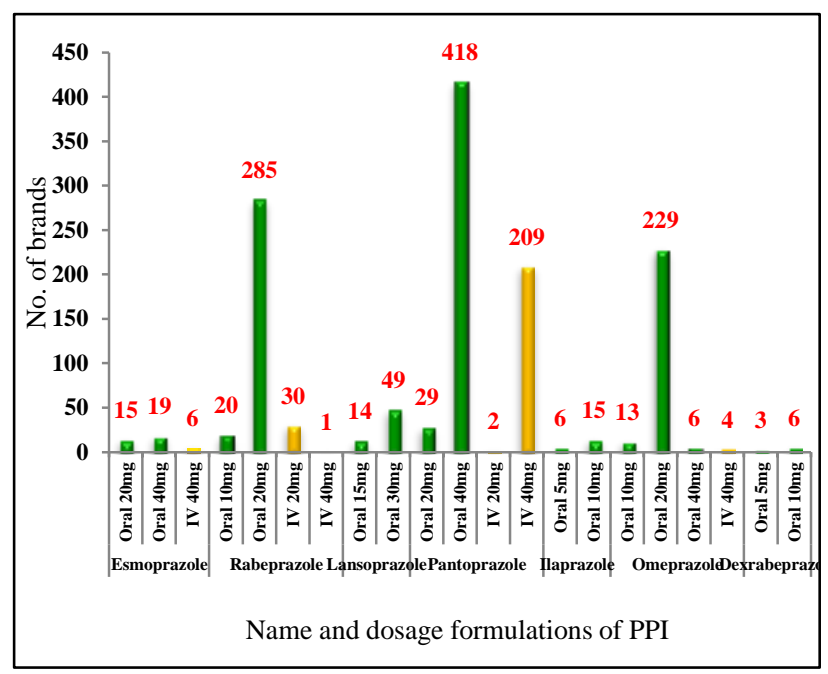

\section{Figure 2: Total number of brands available for each dosage formulations.}

Cost of oral esmoprazole for $20 \mathrm{mg}$ ranges from 17-45 INR with cost ratio 2.65 , for $40 \mathrm{mg}$ ranges from 23-65 INR with cost ratio 2.83. Cost of oral rabeprazole for 10 $\mathrm{mg}$ ranges from 5-45 INR with cost ratio 9, for $20 \mathrm{mg}$ ranges from 9.50- 86.5 INR with cost ratio 9.11. Cost of oral lansoprazole for $15 \mathrm{mg}$ ranges from 21.80-52.50 INR with cost ratio 2.41 , for $30 \mathrm{mg}$ ranges from $41-82$ INR with cost ratio 2. Cost of oral pantoprazole for $20 \mathrm{mg}$ ranges from $18.55-58$ INR with cost ratio 3.13 , for $40 \mathrm{mg}$ 
ranges from 13.33-99 INR with cost ratio 7.43. Cost of oral ilaprazole for $5 \mathrm{mg}$ ranges from 31.65-54.50 INR with cost ratio 1.72 and for $10 \mathrm{mg}$ ranges from $66.40-96$ INR with cost ratio 1.45 . Cost of oral omeprazole for 10 mg ranges from 19.80-25.50 INR with cost ratio 1.29, for $20 \mathrm{mg}$ ranges from 4-105 INR with cost ratio 26.25 , for
$40 \mathrm{mg}$ ranges from 39-85.28 INR with cost ratio 2 . Cost of oral dexrabeprazole for $5 \mathrm{mg}$ ranges from 18-71 INR with cost ratio 3.94 and for $10 \mathrm{mg}$ ranges from 35-86 INR with cost ratio 2.46 (Table 1).

Table 1: Proton pump inhibitors with their number of brands, minimum and maximum price, cost range, cost ratio and mean cost of each formulation.

\begin{tabular}{|c|c|c|c|c|c|c|c|}
\hline $\begin{array}{l}\text { Drug and } \\
\text { formulations }\end{array}$ & Formulations & $\begin{array}{l}\text { Total } \\
\text { brands }\end{array}$ & $\begin{array}{l}\text { Minimum } \\
\text { price }\end{array}$ & $\begin{array}{l}\text { Maximum } \\
\text { price }\end{array}$ & Cost range & $\begin{array}{l}\text { Cost } \\
\text { ratio }\end{array}$ & Mean cost \\
\hline \multicolumn{8}{|c|}{ Oral Preparations } \\
\hline \multirow[t]{2}{*}{ Esmoprazole } & Oral $20 \mathrm{mg}$ & 15 & 17 & 45 & 28 & 2.65 & 28.98 \\
\hline & Oral $40 \mathrm{mg}$ & 19 & 23 & 65 & 42 & 2.83 & 48.94 \\
\hline \multirow[t]{2}{*}{ Rabeprazole } & Oral $10 \mathrm{mg}$ & 20 & 5 & 45 & 40 & 9.00 & 23.13 \\
\hline & Oral $20 \mathrm{mg}$ & 285 & 9.5 & 86.5 & 77 & 9.11 & 44.57 \\
\hline \multirow[t]{2}{*}{ Lansoprazole } & Oral $15 \mathrm{mg}$ & 14 & 21.8 & 52.5 & 30.7 & 2.41 & 28.98 \\
\hline & Oral $30 \mathrm{mg}$ & 49 & 41 & 82 & 41 & 2.00 & 45.39 \\
\hline \multirow[t]{2}{*}{ Pantoprazole } & Oral $20 \mathrm{mg}$ & 29 & 18.55 & 58 & 39.45 & 3.13 & 36.25 \\
\hline & Oral $40 \mathrm{mg}$ & 418 & 13.33 & 99 & 85.67 & 7.43 & 76.47 \\
\hline \multirow[t]{2}{*}{ Ilaprazole } & Oral $5 \mathrm{mg}$ & 6 & 31.65 & 54.5 & 22.85 & 1.72 & 47.5 \\
\hline & Oral $10 \mathrm{mg}$ & 15 & 66.4 & 96 & 29.6 & 1.45 & 72.3 \\
\hline \multirow[t]{3}{*}{ Omeprazole } & Oral $10 \mathrm{mg}$ & 13 & 19.8 & 25.5 & 5.7 & 1.29 & 23.84 \\
\hline & Oral $20 \mathrm{mg}$ & 229 & 4 & 105 & 101 & 26.25 & 37.70 \\
\hline & Oral $40 \mathrm{mg}$ & 6 & 39 & 85.28 & 46.28 & 2.19 & 61.09 \\
\hline \multirow[t]{2}{*}{ Dexrabeprazole } & Oral $5 \mathrm{mg}$ & 3 & 18 & 71 & 53 & 3.94 & 48.6 \\
\hline & Oral $10 \mathrm{mg}$ & 6 & 35 & 86 & 51 & 2.46 & 53.9 \\
\hline \multicolumn{8}{|c|}{ Injectable preparations } \\
\hline Esmoprazole & IV $40 \mathrm{mg}$ & 6 & 63 & 95.70 & 32.7 & 1.52 & 80.83 \\
\hline \multirow[t]{2}{*}{ Rabeprazole } & IV $20 \mathrm{mg}$ & 30 & 46 & 89 & 43 & 1.93 & 64.87 \\
\hline & IV $40 \mathrm{mg} \#$ & 1 & 68.8 & - & - & - & 68.8 \\
\hline \multirow[t]{2}{*}{ Pantaprazole } & IV $20 \mathrm{mg}$ & 2 & 54.39 & 79.5 & 25.11 & 1.46 & 66.94 \\
\hline & IV $40 \mathrm{mg}$ & 209 & 41 & 168 & 127 & 4.10 & 56.89 \\
\hline Omeprazole & IV $40 \mathrm{mg}$ & 4 & 23.25 & 43 & 19.75 & 1.85 & 30 \\
\hline
\end{tabular}

$\# \rightarrow$ only one price is available; hence cost-range and cost-ratio cannot be calculated

Whereas for injectable esmoprazole, cost range of $40 \mathrm{mg}$ is 63-95.70 INR and cost ratio is 1.52. Cost range of injectable rabeprazole for $20 \mathrm{mg}$ ranges from 46-89 INR with cost ratio 1.93 and for $40 \mathrm{mg}$ is 68.80 INR. Injectable pantoprazole has cost range 54.39-79.50 INR for $20 \mathrm{mg}$ with cost ratio 1.461 , cost range is $41-168$ INR for $40 \mathrm{mg}$ with cost ratio 4.10 . While $40 \mathrm{mg}$ injectable omeprazole has cost range 23.25-43 INR and cost ratio of 1.85 (Table 1).

We have calculated mean cost for all the available dosage form of PPIs in Indian market, which are listed in Table 1. Mean cost of esmoprazole $20 \mathrm{mg}$ oral, $40 \mathrm{mg}$ oral and 40 mg IV are INR 28.98, INR 48.94 and INR 77.86 respectively. Mean cost of rabeprazole $10 \mathrm{mg}$ oral, $20 \mathrm{mg}$ oral, $20 \mathrm{mg}$ IV and $40 \mathrm{mg}$ IV are INR 23.13, INR 44.57, INR 61.20 and INR 68.80 respectively.
Mean cost of lansoprazole $15 \mathrm{mg}$ and $30 \mathrm{mg}$ oral are INR 28.98 and INR 45.39 respectively. Mean cost for pantoprazole $20 \mathrm{mg}$ oral, $40 \mathrm{mg}$ oral, $20 \mathrm{mg}$ IV and $40 \mathrm{mg}$ IV are INR 36.25, INR 76.47, INR 66.94 and INR 56.89 respectively. Mean cost for ilaprazole $5 \mathrm{mg}$ and $10 \mathrm{mg}$ oral are INR 47.50 and INR 72.30 respectively. Mean cost for omeprazole $10 \mathrm{mg}, 20 \mathrm{mg}$ oral, $40 \mathrm{mg}$ oral and $40 \mathrm{mg}$ IV are INR 23.84, INR 37.70, INR 61.09 and INR 30 respectively. Mean cost of dexrabeprazole $5 \mathrm{mg}$ oral and $10 \mathrm{mg}$ oral are INR 48.60 and INR 53.90 respectively (Table 1).

\section{DISCUSSION}

PPIs are the prodrugs which are activated in an acid environment of stomach. Activated drug binds to sulfhydril groups of cysteines in gastric $\mathrm{H}^{+} \mathrm{K}^{+}$ATPase to 
inactivate these pumps irreversibly. Hence acid secretion requires synthesis of new pump molecule. PPIs inhibit daily gastric acid production by $80 \%-95 \%$ in typical therapeutic doses for 24-48 hours. They are effective in suppressing gastric acid secretion irrespective of the other stimulating factors. $^{8}$ Around $51.4 \%$ of outpatient department patients are prescribed PPIs in their prescription. In hospitalized patients prescription of these drugs is also around $80 \% .^{13,14}$ Since, PPIs consume a large portion of the budget of the patient expenditure. This adversely affects the compliance of the patients. This study can help the doctors to choose the best PPIs depending on the economic status of the patient.

Pantoprazole is the most commonly available PPIs with 494 brands, followed by 297 brands of rabeprazole. Recently marketed PPIs dexrabeprazole has least numbers of marketed brands i.e., 6 brands only. All the PPIs are available in oral and injectable formulations except lansoprazole, ilaprazole and dexrabeprazole which are available in oral formulations only.

Omeprazole $20 \mathrm{mg}$ and $40 \mathrm{mg}$ is the cheapest in both oral and injectable form respectively while ilaprazole $10 \mathrm{mg}$ is the costliest amongst all oral formulations and rabeprazole $40 \mathrm{mg}$ is the costliest in injectable preparations available in the market. Amongst oral preparations, omeprazole $20 \mathrm{mg}$ is also having the most expensive brand while pantoprazole $40 \mathrm{mg}$ has the costliest brand amongst injectable PPIs. This may be because omeprazole is the oldest approved PPI. It is available in various generic formulations making it the cheapest PPI brand. Ilaprazole is newly approved PPI. Therefore non availability in generic formulation makes it the costliest drug in oral formulations.

By considering mean cost of all the brands, rabeprazole $10 \mathrm{mg}$ is the cheapest oral PPI and pantoprazole $40 \mathrm{mg}$ is the costliest PPI with mean cost of INR 76.47 while esmoprazole $40 \mathrm{mg}$ and omeprazole $40 \mathrm{mg}$ are having the highest and lowest mean cost for the injectable PPIs.

Highest and the smallest cost range in oral preparations of PPIs is for omeprazole $20 \mathrm{mg}$ and omeprazole $10 \mathrm{mg}$ respectively. In injectable preparations pantoprazole 40 $\mathrm{mg}$ and omeprazole $40 \mathrm{mg}$ respectively have the highest and lowest cost range.

Highest cost ratio for oral PPIs is for omeprazole $20 \mathrm{mg}$ and lowest is for omeprazole $10 \mathrm{mg}$. This variation is mostly due to large numbers of brands (229) available for omeprazole $20 \mathrm{mg}$. For injectable formulations, highest and lowest cost ratios are for pantoprazole $40 \mathrm{mg}$ and 20 $\mathrm{mg}$ respectively. This might be because of availability of large number of brands for injectable pantoprazole $40 \mathrm{mg}$ (209). The no. of brands for injectable pantoprazole 20 $\mathrm{mg}$ are only 2 which might be responsible for its lowest cost ratio. Least pharmacokinetic interactions amongst first generation PPIs along with availability in generic forms favour the highest number of pantaprazole prescription amongst PPIs in India and might be the reason for highest availability of oral and injectable brands of pantaprazole, ultimately the mean cost is highest for oral pantaprazole and injectable pantoprazole is also having costliest brand, highest cost range and cost ratio. $^{15,16}$

A decrease in drug expenditure can be achieved by changing PPIs prescribing practices. As all PPIs are equally effective, cost of treatment can be easily lowered without compromising clinical efficacy. This will be helpful in increasing the compliance of the patient to any drug therapy.

\section{CONCLUSION}

PPIs are prescribed in large numbers in day to day practice. Prescription of costly brands adversely affects expenditure on health care system, patient's economy and thereby their health seeking behavior. Therefore knowledge of the doctor about drug cost and its application in practice would be an added benefit to the patient and society.

We have included only those brands of PPIs which are mentioned in the CIMS India and Drug today India only. Therefore, few brands might have been missed which are not mentioned in these two index. Also, various fixed dose combinations (FDC) of these PPIs with many other drugs are not taken into consideration while doing this study. Prices of all the available brands are not included in the analysis, as few brands are mentioned in the CIMS and Drug Today without mentioning there price.

Funding: No funding sources

Conflict of interest: None declared

Ethical approval: The study was approved by the Institutional Ethics Committee

\section{REFERENCES}

1. Moore M, Gould P, Keary BS. Global urbanization and impact on health. Int $\mathrm{J}$ Hyg Environ Health. 2003;206:269-78.

2. Ibrahim H, Awadalla. Health effect of slums: A consequence of urbanization. Serbian Journal of Management. 2013;3:7-14.

3. Mohammed KM, Suman C, Bogadi V, Prabhakar B, Rao KPR, Devi S, et al. Epidemic trends of upper gastrointestinal tract abnormalities: hospital-based study on endoscopic data evaluation. Asian Pac J Cancer Prev. 2015;16(14):5741-7.

4. Sharma PK, Ahuja V, Madan K, Gupta S, Raizada A, Sharma MP. Prevalence, severity, and risk factors of symptomatic gastroesophageal reflux disease among employees of a large hospital in Northern India. Indian J Gastroenterol. 2011;30(3):128-34.

5. Goh KL. Changing epidemiology of gastrooesophageal reflux disease in the Asia-Pacific 
region: an overview. J Gastroenterol Hepatol. 2004;19:22-5.

6. Ho KY, Lim LS, Goh WT, Lee JMJ. The prevalence of gastrooesophageal reflux has increased in Asia: a longitudinal study in the community. J Gastroenterol Hepatol. 2002;16:132.

7. Barkun A, Leontiadis G. Systematic review of the symptom burden, quality of life impairment and costs associated with peptic ulcer disease. Am J Med. 2010;123(4):358-66.

8. Wallace JL, Sharkey KA. Pharmacotherapy of gastric acidity, peptic ulcers and gastroesophageal reflux disease. In: Bruxton LI, Chabner BA, Knollman BC. Goodman and Gilman's The Pharmacological basis of therapeutics. $12^{\text {th }}$ ed. New York, NY: McGraw-Hill; 2012:1311-1133.

9. CIMS India. Monthly index of medical specialties. c 2015 (3). Available at https://www.mims.com/. Accessed 27 October 2015.

10. Drug Today India. Ready reckoner of current medical formulations. 2015 (3). Available at https://www.drugtodayonline.com/drugdirectory/pha rmacological-index.html. Accessed 22 October 2015.
11. Eisenberg JM. Clinical economics: a guide to economic analysis of clinical practices. J Am Med Asso. 1989;262(20):2879-86.

12. Sharma HL, Sharma KK. Treatment of gastric acidity, peptic ulcer and gastroesophageal reflux disease. In: Principles of Pharmacology. $2^{\text {nd }}$ ed. Hyderabad, Paras publications; 2011:389-90.

13. Villamanan BE. Reasons for initiation of proton pump inhibitor therapy for hospitalized patients and its impact on outpatient prescription in primary care. Rev Esp Enferm Dig 2015.

14. Solis GPJ, Perez PM, Fernandez JP, Maranes AI. Inappropriate use of proton pump inhibitors, guidelines and clinical research. Rev Esp Enferm Dig. 2013;105:373.

15. Ralph SW, Henning B. Pharmacokinetic drug interaction profiles of proton pump inhibitors: an update. Drug Safety. 2014;37:201-11.

16. Patil R, Aithal S, Hooli T, Varun HV. Drug utilisation study of proton pumps inhibitors in inpatients of a tertiary care hospital: a crosssectional study. Natl J Integr Res Med. 2015;6(5):62-5.

Cite this article as: Bargade MB, Mahatme MS, Hiware S, Admane PD. Cost-minimization analysis of proton pump inhibitors in India. Int $\mathbf{J}$ Basic Clin Pharmacol 2016;5:1043-7. 